\title{
Spatio-temporal patterns in demersal elasmobranchs from trawl surveys in the eastern English Channel (1988-2008)
}

\author{
C. S. Martin ${ }^{1}$, S. Vaz $^{1, *}$, J. R. Ellis ${ }^{2}$, F. Coppin ${ }^{1}$, D. Le Roy ${ }^{1}$, A. Carpentier $^{1}$ \\ ${ }^{1}$ Laboratoire ressources halieutiques, Institut français de recherche pour l'exploitation de la mer (IFREMER), \\ 150 quai Gambetta, 62321 Boulogne-sur-mer, France \\ ${ }^{2}$ Lowestoft Laboratory, Centre for Environment, Fisheries \& Aquaculture Science (Cefas), Pakefield Road, \\ Lowestoft NR33 0HT, UK
}

\begin{abstract}
Elasmobranchs have life-history characteristics that make them more vulnerable to fishing than many teleost fish. As commercial landings data are usually not sufficient for the monitoring and assessment of elasmobranchs, fisheries-independent data, geostatistics and Geographic Information Systems were used to investigate the spatio-temporal patterns of sharks (6 species), skates (9 species) and stingray in the eastern English Channel. Temporal trends in relative abundance and distributions of total-length frequencies were investigated using data collected over $21 \mathrm{yr}$ from an annual survey using a Grande Ouverture Verticale (GOV) trawl. Temporal trends in relative abundance were examined qualitatively in relation to the reported conservation status for the various species. Most individuals captured for 7 of the species were immature. The GOV trawl was more efficient at sampling demersal sharks than batoids (skates and rays), especially small-sized batoids. Geostatistics were effectively used to explore, identify and quantify the spatial structure of the distributions of 13 species. The more abundant species displayed significantly larger patch diameters. Three shark species (Scyliorhinus canicula, S. stellaris and Galeorhinus galeus) were found to be spatially segregated by sex. The shark species tended to occur in the deeper waters of the area, while skates were found to be more coastal in their distribution. Results have contributed to a greater understanding of the spatio-temporal patterns in elasmobranch species in the eastern English Channel and are of relevance to future marine spatial planning and the development of long-term management plans for elasmobranchs in the area and elsewhere.
\end{abstract}

KEY WORDS: Elasmobranchii - Chondrichthyes - Kriging · GIS · Conservation · Sex ratio · Catchability · Channel Ground Fish Survey · CGFS

\section{INTRODUCTION}

Elasmobranchs (sharks, skates and rays) are more vulnerable to fishing than many teleost fish because of their slow population growth resulting from their late age at maturity, longevity, low fecundity and long gestation period (Stevens et al. 2000, Compagno et al. 2005, Ellis et al. 2008a). Furthermore, many elasmobranch stocks have not traditionally been managed, despite often being an important bycatch in mixed fisheries, particularly those targeting demersal teleosts
(Shotton 1999). Discarded bycatch is not reported, and landed bycatch may only be recorded in official statistics under generic landings categories (Stevens et al. 2000), although species-specific data collection has improved in recent years. Some of the larger-bodied elasmobranchs have life-history characteristics and behaviours that increase their vulnerability to exploitation, including reduced recovery rates and increased risks of extirpation (Jennings et al. 1999, Walker 1999, Stevens et al. 2000, Dulvy \& Reynolds 2002). Elasmobranchs are often important components of regional 
fish communities (e.g. in the eastern English Channel; Vaz et al. 2007) and of marine food webs (Stevens et al. 2000, Mackinson \& Daskalov 2007), preying on a wide variety of polychaetes, crustaceans, molluscs and fish, depending on the species and size (Ellis et al. 1996). Some elasmobranch populations are also known to be spatially segregated by size and/or sex, due to differences in behaviour and habitat preferences (Springer 1967, Pawson 1995, Sims et al. 2001, Mucientes et al. 2009). Important population components such as juveniles and reproductively active females may, therefore, be more readily exposed to exploitation than other population components.

Commercial landings data are usually not sufficient to monitor and assess the many elasmobranch species that are exploited in mixed fisheries. Discards at sea tend to be unevaluated and, thus, data on total dead removals (dead discards plus declared landings) are generally unavailable (Bonfil 1994), while declared landings may only be reported in generic categories (e.g. 'skates and rays', 'dogfish and hounds'). Many fishery-independent scientific trawl surveys are designed to optimise the sampling of commercial teleosts, and may include erroneous records for some elasmobranch taxa (Ellis et al. 2005a,b, Maxwell \& Jennings 2005). Nevertheless, such surveys can provide the only species-specific information on trends in relative abundance and spatial distribution for demersal elasmobranchs for which commercial catch data and/or lifehistory information (e.g. stock identity, age and sex composition, and reproductive biology) are often limited or even lacking (Ellis et al. 2005a,b). Fisheryindependent surveys using trawl, gillnets or longlines are commonly used to sample elasmobranchs (Musick \& Bonfil 2005). Large individuals often swim faster than the towing speeds of mobile (or 'active') gear such as trawl, and are therefore less likely to be captured in such gears. In contrast, smaller, bottom-dwelling species such as batoids, dogfish and catsharks are more likely to be captured by mobile gear, such as the bottom trawl used in the present study.

The present study aimed to increase the knowledge with which to determine this vulnerable group's status in the eastern English Channel (Fig. 1a). This was notably achieved through the examination of temporal trends (spanning $21 \mathrm{yr}$ ) in relative abundance and of length and sex frequency distributions. Quantitative methods, including geostatistics and Geographic Information Systems (GIS), were used to investigate the spatial patterns of the various species, including their possible spatial segregation by taxonomic group and sex. Given the vulnerability of elasmobranch species, this knowledge is of critical importance to marine resources managers and spatial planners in a heavily exploited marine ecosystem.

\section{MATERIALS AND METHODS}

Study area and data collection. The eastern English Channel is a shallow epicontinental sea, characterised by a heterogeneous environment. It supports important fisheries, shipping lanes and sites of aggregate extraction, as well as spawning, nursery and feeding areas for a number of marine species (Vaz et al. 2007, Carpentier et al. 2009, Martin et al. 2009, 2010). Between 1988 and 2008, the Institut français de recherche pour l'exploitation de la mer (IFREMER) carried out the Channel Ground Fish Survey (CGFS), a fishery-independent trawl survey under the auspices
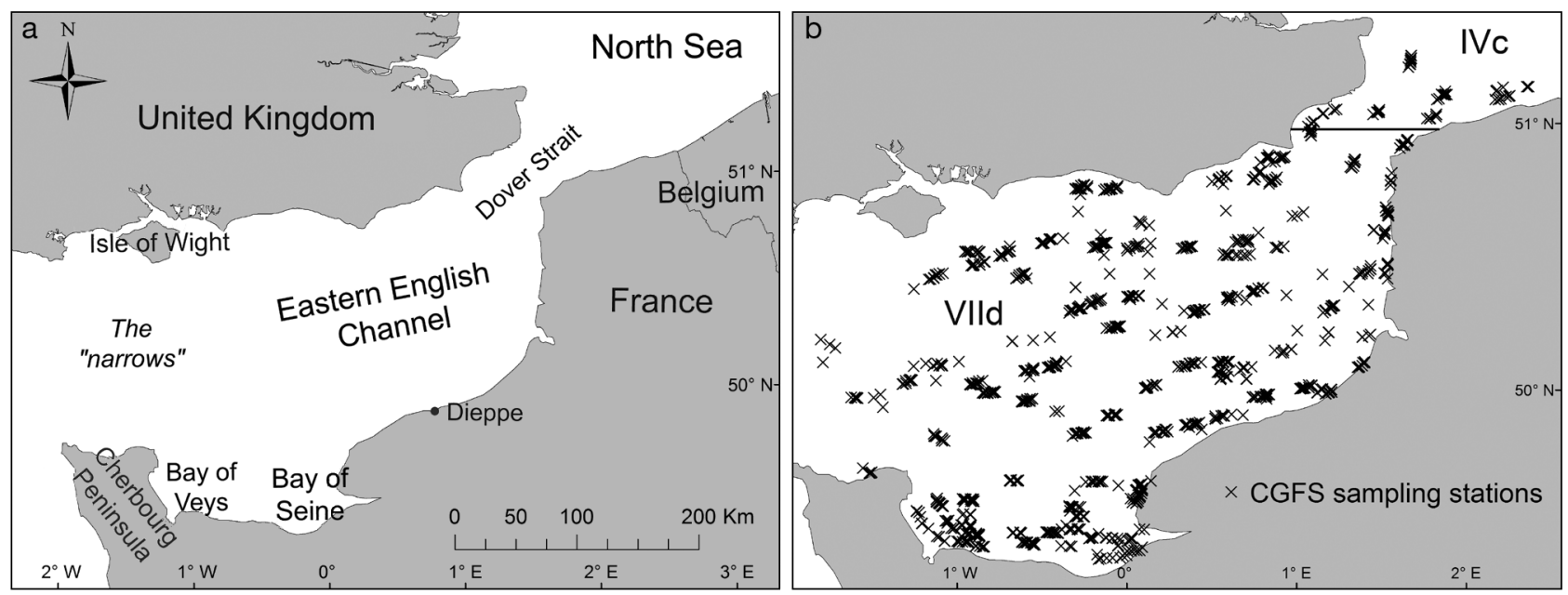

Fig. 1. (a) The eastern English Channel and geographical locations mentioned in the text, and (b) stations sampled during the Channel Ground Fish Survey (CGFS; 1988 to 2008) where darker symbols indicate several stations at the same location. ICES Divisions VIId and (part of) IVc are indicated in (b) 
of the International Council for the Exploration of the Sea (ICES) International Bottom Trawl Survey Working Group (IBTSWG). This survey aimed to provide catch data to support the assessment of the main commercial fish stocks present in this area.

The CGFS study area (which comprised ICES Divisions VIId and part of $\mathrm{IVC}_{\text {; }}$ Fig. 1b) was divided into rectangles of 15' latitude and 15' longitude using a systematic sampling strategy (Coppin et al. 2001, Vaz et al. 2007, ICES 2010). At least one $30 \mathrm{~min}$ haul was performed in each rectangle during daylight hours, at an average speed of 3.5 knots (range: 2.5 to 4 knots). A total of 60 to 110 stations were sampled each year in October (Fig. 1b), although not all stations were fished every year as a result of weather conditions, gear damage and ship failure. The sampling gear used on RV 'Gwen-Drez' (a 24.5 m stern trawler) was a Grande Ouverture Verticale (GOV) bottom trawl with a high (ca. 3 m) headline height, well suited for catching demersal and bentho-pelagic species. The lengths of the headline and groundrope were 19.7 and $25.9 \mathrm{~m}$, respectively, and the horizontal trawl opening $10 \mathrm{~m}$. In order to catch juveniles, the codend had a liner of $20 \mathrm{~mm}$ (stretched) mesh size. To record and maintain net geometry, SCANMAR sensors (SCANMAR AS, Norway) were used (from 1997). The sampling gear was sized according to ship power and was suited to the various seabed types encountered in the study area.

At each sampling station, fish species were sorted, weighed, counted and measured (total length, to the whole $\mathrm{cm}$ below for elasmobranchs). Catches were fully processed unless very large ( $>150 \mathrm{~kg}$ at any given station). In these cases, the whole catch was processed for the less common species and a homogeneous mix (e.g. of 2 or 3 species) sorted. The only elasmobranch species sub-sampled in this way was Scyliorhinus canicula. Between 1991 and 2008, elasmobranchs were sexed; this information was used to estimate the sex ratio (presented here as the proportion of females, $\% F)$ at individual stations. Elasmobranch densities $(x)$, or relative abundance, from a total of 1843 trawl hauls made in the period from 1988 to 2008, were expressed as numbers of individuals per $\mathrm{km}^{2}$. Densities were left uncorrected for species catchability due to differences in sampling gear selectivity. Selectivity may be defined as the proportion of individuals encountering the gear and actually being captured by it. It is a complex function of fishing gear (metrics and design) and fish size, and is not well understood for elasmobranchs (Musick \& Bonfil 2005).

Data analyses. Survey density data were tested for normality (using histograms, skewness and kurtosis) and were $\log$-transformed $\left(\log _{10}[x+1], x=\right.$ density) so as to reduce the skewed distribution (Legendre \& Legendre 1998). Mean annual densities were estimated across the study area using transformed data, and then plotted as temporal trends. Mean sex ratios across the study area and associated confidence intervals (CI) at $95 \%$ were calculated, though only if there were $\geq 10$ stations where sex had been recorded. CI calculations took into account the number of degrees of freedom (df), calculated as df = number of stations -1 .

Cartography. Depending on the number of stations where each species occurred and based on expert knowledge and experience, their spatial distributions were plotted as (1) point maps (for the 3 species that were reported at $<10$ stations), (2) continuous presence probability maps (for the 4 species that occurred at $10<$ stations $<50$ ) or (3) continuous density maps (for the 9 most commonly occurring species). Continuous maps were produced by kriging interpolation (see 'Materials and methods - geostatistical analyses') on data pooled over the period of study. Presence probability maps were created using binary data, i.e. survey data coded as presence (1) or absence (0) at individual stations.

Geostatistical analyses. Species spatial patterns may be investigated with geostatistics, a suite of methods for analysing and interpolating spatial data (Webster \& Oliver 2001). Geostatistics are used to estimate, at nonsampled locations, the values of a property of interest (e.g. species density) from a grid of point-source data. Geostatistical estimation (or kriging) is different from other interpolation methods because it uses a model, the variogram, describing the spatial structure and variation in the data, and produces an estimation of the interpolation error (measured as variance). Variogram parameters can also be used to explore, identify and quantify the spatial structure of distributions (e.g. Petitgas 2001, Mello \& Rose 2005, Vaz et al. 2005), in relation to species habitat preferences and spatial behaviour (e.g. aggregation, segregation, seasonal variation, ontogenic shift).

For each species mapped by interpolation, Genstat software (Payne et al. 2008) was used to fit the corresponding variograms by least-squares approximation and to estimate their main parameters (sill variance, nugget variance, and lag distance or 'range'). These parameters were then used to krige either the species densities (by ordinary kriging) or presence probabilities (by indicator kriging) on a regular grid of latitudes and longitudes, coincident with the areas sampled during the survey and at the same resolution as the survey (0.1 decimal degree or $0.1 \mathrm{dd}$ ). A grid of interpolation variances (i.e. squared errors) was also produced during each kriging procedure, to give an idea of the reliability of the kriged estimates. The grids of kriged values and interpolation variances were then smoothed within a GIS (ESRI ArcMap 9.2, 1999 to 2006) to produce continuous spatial distributions. Further details 
on the methodology can be found in Webster \& Oliver (2001), Vaz et al. (2005) and Carpentier et al. (2009).

The range $(D ; 0.1 \mathrm{dd}$ of latitude $\approx 11.4 \mathrm{~km})$, which marked the limit of spatial dependence, indicated the average diameter of patches (Webster \& Oliver 2001). Furthermore, the extent of spatial structuring (i.e. the proportion of data variability) explained by the variogram was estimated using the ratio $Q$ calculated as follows:

$$
Q=C /\left(C+C_{0}\right)
$$

where $C$ was the variance attributable to spatial dependence, $C_{0}$ the nugget variance, and the sum $(C+$ $C_{0}$ ) the sill variance (i.e. the maximum variance in the data). The nugget was the amount of variance not explained by the spatial model and arising mostly from variation occurring over distances smaller than the sampling interval. $Q$ was null in the case of 'flat' or 'pure nugget' variograms (modelled by a constant value equal to the sill variance); this indicated the absence of detectable spatial dependence at the survey scale, although the spatial heterogeneity of the species might have occurred at a finer scale than that of the survey. As $Q$ increased, a greater proportion of the data variability could be explained by the variogram model. High values of $Q$ (up to a maximum of 1 ) indicated that the species' distribution was strongly structured in space, suggesting for instance that it could have a strong affinity to a particular habitat.

For a number of species (data permitting), the relative proportions of females and males at sampling stations were also interpolated. The resulting continuous maps (with values between 0 and 1) were then used to weigh, within a GIS, the corresponding density maps (showing both sexes together) so as to visualise potential spatial segregations by sex. Finally, spatial patterns of the 'shark' and 'skate' taxonomic groups were investigated by producing, also within a GIS, 2 corresponding combined maps. First, all continuous maps showing species distributions were centred and standardised so that they ranged between 0 and 1 (this did not affect their spatial patterns), and would carry the same weight in the next calculation. Then, the shark and skate maps were produced by averaging the corresponding centred and standardised maps. The resulting combined maps can be understood to show presence probabilities for sharks and for skates. For the species shown as point maps, stations where these species were caught, if any, were added as black dots on the corresponding combined shark or skate maps.

\section{RESULTS}

\section{Species captured}

Overall, 16 elasmobranch species were captured by GOV trawl during CGFS surveys (1988 to 2008) (Table 1). Of the 10 batoid species (skates and rays), only 1 ray species (Dasyatis pastinaca, ovoviviparous reproduction) was encountered, the other 9 species being skates (rajids, oviparous reproduction). Six shark species were encountered, of which scyliorhinids ( 2 species) and triakids ( 3 species) were the most frequent. Of these 16 species, 2 sharks (Squalus acanthias and Galeorhinus galeus) and 9 batoids were only

Table 1. Elasmobranch species captured during the Channel Ground Fish Survey (1988 to 2008), along with their IUCN Red List status. Species authority and IUCN status from IUCN (2010). RY: ray, SK: skate, SH: shark, DD: Data Deficient, LC: Least Concern, NT: Near Threatened, VU: Vulnerable, EN: Endangered, CR: Critically Endangered, NEA: Northeast Atlantic

\begin{tabular}{|c|c|c|c|c|c|}
\hline Family & Species & Species authority & Common name & Group & $\begin{array}{l}\text { IUCN } \\
\text { status }\end{array}$ \\
\hline Dasyatidae & Dasyatis pastinaca & (Linnaeus, 1758) & Common stingray & RY & NT in NEA \\
\hline \multirow[t]{9}{*}{ Rajidae } & Amblyraja radiata & (Donovan, 1808) & Thorny skate, starry ray & SK & LC in NEA \\
\hline & Leucoraja circularis & (Couch, 1838) & Sandy ray & SK & VU in NEA \\
\hline & L. fullonica & (Linnaeus, 1758) & Shagreen ray & SK & NT \\
\hline & L. naevus & (Müller \& Henle, 1841) & Cuckoo ray & SK & LC \\
\hline & Raja brachyura & (Lafont, 1873) & Blonde ray & SK & NT \\
\hline & R. clavata & Linnaeus, 1758 & Thornback skate, roker & SK & NT \\
\hline & R. microocellata & (Montagu, 1818) & Small-eyed ray & SK & NT \\
\hline & R. montagui & (Fowler, 1910) & Spotted ray & SK & LC \\
\hline & R. undulata & Lacepède, 1802 & Undulate ray & SK & EN \\
\hline \multirow[t]{2}{*}{ Scyliorhinidae } & Scyliorhinus canicula & (Linnaeus, 1758) & Lesser spotted dogfish & $\mathrm{SH}$ & $\mathrm{LC}$ \\
\hline & Scyliorhinus stellaris & (Linnaeus, 1758) & Nursehound & $\mathrm{SH}$ & NT \\
\hline Squalidae & Squalus acanthias & Linnaeus, 1758 & Spurdog & $\mathrm{SH}$ & CR in NEA \\
\hline \multirow[t]{3}{*}{ Triakidae } & Galeorhinus galeus & (Linnaeus, 1758) & Tope & $\mathrm{SH}$ & DD in NEA \\
\hline & Mustelus asterias & Cloquet, 1821 & Starry smooth-hound & $\mathrm{SH}$ & LC in NEA \\
\hline & M. mustelus & (Linnaeus, 1758) & Smooth-hound & $\mathrm{SH}$ & DD in NEA \\
\hline
\end{tabular}


recorded in small numbers (each species representing $<4 \%$ of the total elasmobranch density; Table 2, Fig. 2). Raja clavata, Scyliorhinus spp. (2 species) and Mustelus spp. (2 nominal species) represented $88.0 \%$ of the cumulative density. In terms of the total numbers of individuals captured (Table 2), Scyliorhinus canicula largely dominated the elasmobranch catches (>24000 individuals in total), followed relatively far behind by $R$. clavata and $M$. asterias (slightly less than 2000 individuals of each). The proportional biomass (Table 2, Fig. 2) was similar to abundance data. There were reports of 1 Leucoraja fullonica, 2 L. circularis and 3 Amblyraja radiata, but these may have been misidentified (see 'Discussion').

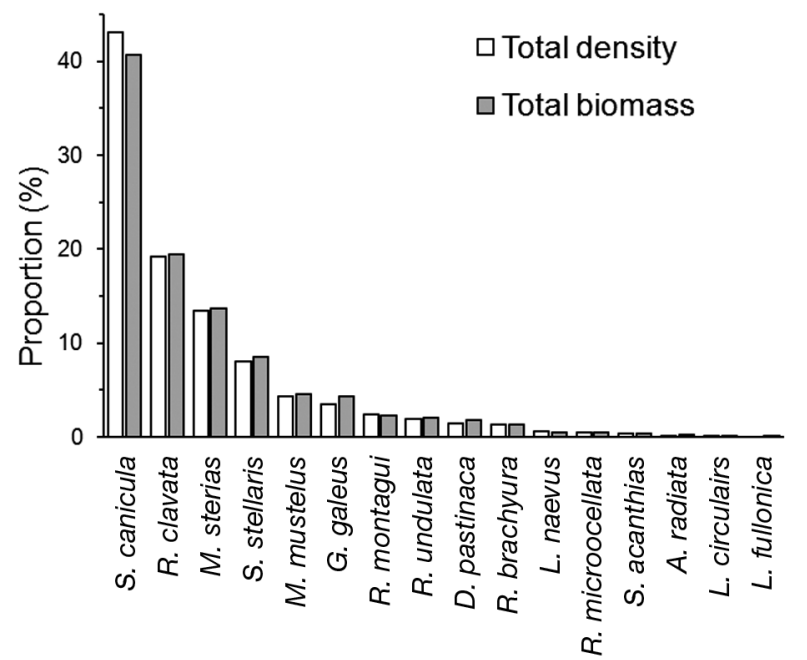

Fig. 2. Ranked proportions of total densities and biomasses for the 16 elasmobranch species captured during the Channel Ground Fish Survey (1988 to 2008). See Table 1 for genus names

\section{Temporal trends}

Temporal trends in mean density across the surveyed area are shown in Fig. 3 for the 8 most abundant species. Squalus acanthias (trend not shown) was last captured in 1998, and its occurrence prior to this was low (on average they were caught twice per survey between 1988 and 1998). Decreasing trends in mean density over the period 1988 to 2008 were perceptible for Raja montagui and Galeorhinus galeus, while increasing trends were apparent for Scyliorhinus canicula, Scyliorhinus stellaris and Mustelus asterias. Given the taxonomic confusion between Mustelus spp., a combined trend was also examined, which also indicated an increasing trend, although this trend was driven by $M$. asterias, the more abundant of the two. Due to low catch rates over the duration of the surveys, further (i.e. quantitative) investigations into the significance of these observed temporal trends were not carried out.

\section{Total lengths and sex}

The ranges of total lengths observed during the CGFS are listed per species in Table 3 and their length frequency distributions (except for Leucoraja circularis and L. fullonica) shown in Fig. 4. Given the lengths at birth $\left(L_{\mathrm{b}}\right)$ listed in Table 3, neonates of 5 species (Raja clavata, Scyliorhinus canicula, S. stellaris, Mustelus asterias and $M$. mustelus) were caught. Most Dasyatis pastinaca, and probably Galeorhinus galeus, individuals captured were longer than at $50 \%$ maturity $\left(L_{\mathrm{m}}\right.$, i.e. the length where $50 \%$ of individuals are mature; see

Table 2. For each species, number of individuals captured, its relative proportion (in terms of density and biomass) in the survey data, the number of stations showing positive occurrence (i.e. non-null density), and the type of spatial distribution map produced

\begin{tabular}{|lccccc|}
\hline Species & $\begin{array}{c}\text { Individuals } \\
\text { observed }(\mathrm{n})\end{array}$ & $\begin{array}{c}\text { Total density } \\
(\%)\end{array}$ & $\begin{array}{c}\text { Total biomass } \\
(\%)\end{array}$ & $\begin{array}{c}\text { No. of positive- } \\
\text { occurrence stations }\end{array}$ & $\begin{array}{c}\text { Spatial } \\
\text { distribution }\end{array}$ \\
\hline Dasyatis pastinaca & 86 & 1.40 & 1.79 & 132 & Density \\
Amblyraja radiata & 9 & 0.15 & 0.16 & 5 & Point \\
Leucoraja circularis & 2 & 0.05 & 0.06 & 2 & Point \\
L. fullonica & 1 & 0.03 & 0.05 & 1 & Point \\
L. naevus & 25 & 0.56 & 0.50 & 21 & Presence probability \\
Raja brachyura & 79 & 1.28 & 1.25 & 43 & Presence probability \\
R. clavata & 1931 & 19.18 & 19.41 & 15 & Density \\
$R$. microocellata & 23 & 0.43 & 0.49 & 83 & Presence probability \\
R. montagui & 158 & 2.42 & 2.21 & 67 & Density \\
$R$. undulata & 89 & 1.90 & 2.04 & 262 & Density \\
Scyliorhinus canicula & 24747 & 43.05 & 40.66 & 13 & Density \\
Scyliorhinus stellaris & 900 & 8.02 & 8.52 & 111 & Density \\
Squalus acanthias & 19 & 0.38 & 0.39 & 416 & Presence probability \\
Galeorhinus galeus & 294 & 3.44 & 4.27 & 143 & Density \\
Mustelus asterias & 1799 & 13.45 & 13.65 & 4.55 & Density \\
M. mustelus & 333 & 4.26 & 100.00 & Density \\
Total & 30495 & 100.00 & & & \\
\hline
\end{tabular}



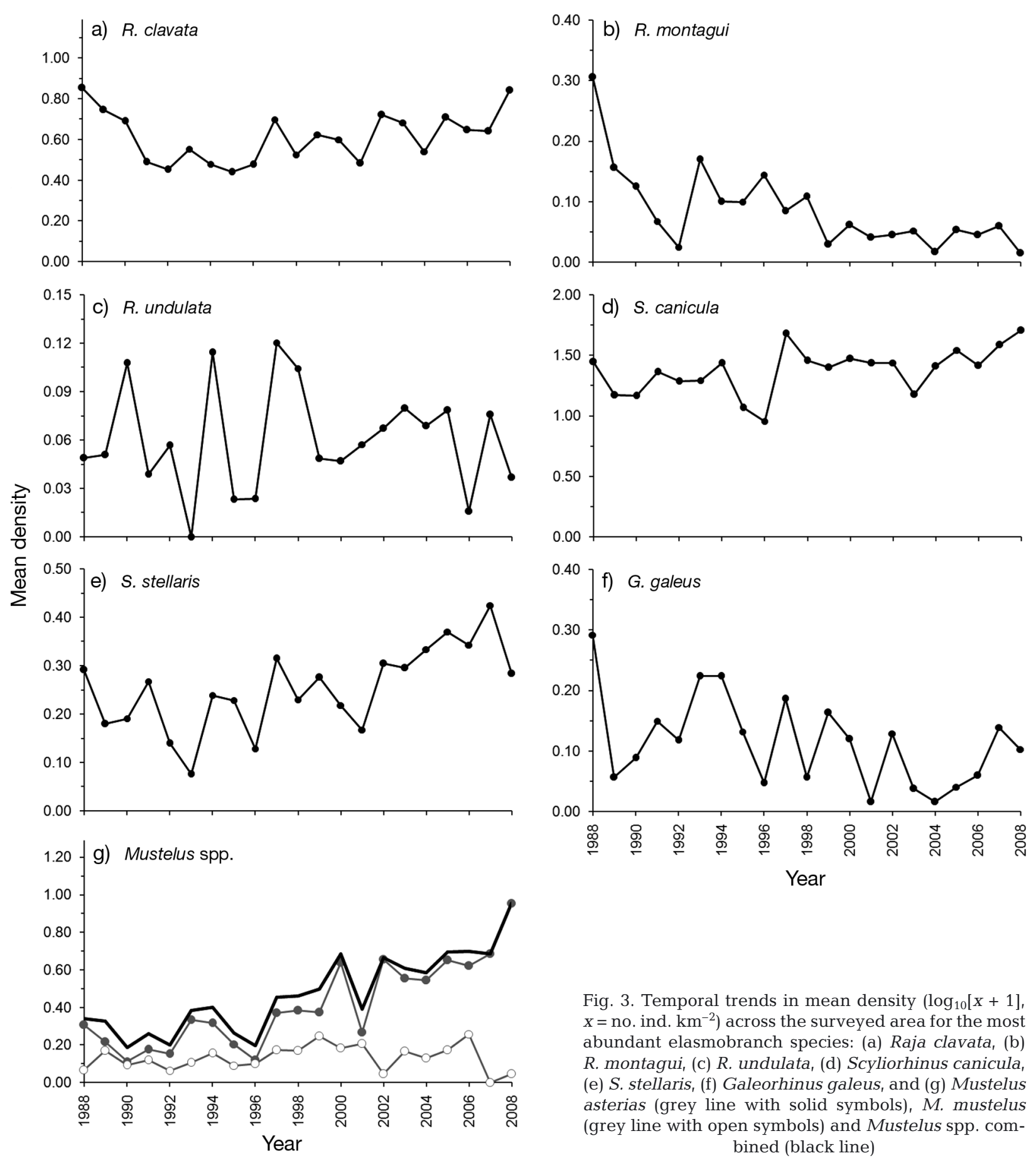

Table 3 for published figures, although the estimated $L_{\mathrm{m}}$ for $G$. galeus [= $69 \mathrm{~cm}$ ] may be too low, J. R. Ellis pers. obs.). Eight out of 9 Amblyraja radiata individuals were probably mature, although the upper size range $\left(L_{\text {max }}=79 \mathrm{~cm}\right)$ observed during the CGFS suggested that some of these individuals may have been misidentified (see 'Discussion'). In contrast, most $R$. clavata, R. montagui, S. canicula, S. stellaris, M. asterias and M. mustelus, and nearly all observed $R$. brachyura

Fig. 3. Temporal trends in mean density $\left(\log _{10}[x+1]\right.$, $x=$ no. ind $\mathrm{km}^{-2}$ ) across the surveyed area for the most abundant elasmobranch species: (a) Raja clavata, (b) R. montagui, (c) R. undulata, (d) Scyliorhinus canicula, (e) S. stellaris, (f) Galeorhinus galeus, and (g) Mustelus asterias (grey line with solid symbols), M. mustelus (grey line with open symbols) and Mustelus spp. combined (black line)

were shorter than $L_{\mathrm{m}}$. The length distribution of $S$. canicula was clearly bimodal, as were those of $M$. asterias and M. mustelus, although to a lesser extent. With the exceptions of $D$. pastinaca and $R$. microocellata, which showed high proportions of females (on average 78.6 and $82.1 \%$, respectively), all other species for which the sex ratio could reasonably be calculated indicated approximately equal sex ratios at individual stations (Table 3). 
Table 3. For each species, range of total lengths (TL) observed during the Channel Ground Fish Survey, length at birth $\left(L_{\mathrm{b}}\right)$ and at $50 \%$ maturity $\left(L_{\mathrm{m}}\right)$, number of stations where sex was recorded, mean proportion of females at individual stations, and whether spatial segregation by sex was investigated (N: no, Y: yes). na: not available, nd: not determined. For range and $L_{\mathrm{m}}$ figures shown in brackets, see 'Discussion'

\begin{tabular}{|c|c|c|c|c|c|c|}
\hline Species & $\begin{array}{l}\text { TL range } \\
(\mathrm{cm})\end{array}$ & $\begin{array}{c}L_{\mathrm{b}} \\
(\mathrm{cm})\end{array}$ & $\begin{array}{c}L_{\mathrm{m}} \\
(\mathrm{cm})\end{array}$ & $\begin{array}{c}\text { No. of } \\
\text { stations where } \\
\text { sex recorded }\end{array}$ & $\begin{array}{l}\text { Mean \% } \\
\text { females } \\
(95 \% \text { CI })\end{array}$ & $\begin{array}{c}\text { Sexual } \\
\text { segregation } \\
\text { investigated }\end{array}$ \\
\hline Dasyatis pastinaca & $28-164$ & $20^{\mathrm{a}}$ & $50 / 60^{\mathrm{a}, \mathrm{f}}$ & 40 & $0.79(0.12)$ & $\mathrm{N}$ \\
\hline Amblyraja radiata & $42-(79)$ & $8-12^{\mathrm{b}}$ & $44^{\mathrm{g}}$ & 9 & nd & $\mathrm{N}$ \\
\hline Leucoraja circularis & 50,70 & na & $85^{\mathrm{h}}$ & 2 & nd & $\mathrm{N}$ \\
\hline L. fullonica & 90 & na & $80^{\mathrm{h}}$ & 1 & nd & $\mathrm{N}$ \\
\hline L. naevus & $27-79$ & $10^{\mathrm{c}}$ & $55^{\mathrm{i}}$ & 19 & $0.50(0.24)$ & $\mathrm{N}$ \\
\hline Raja brachyura & $24-95$ & $16-19^{c}$ & $92^{\mathrm{j}}$ & 41 & $0.64(0.13)$ & $\mathrm{N}$ \\
\hline R. clavata & $12-114$ & $11-13^{\mathrm{c}}$ & $68 / 77^{\mathrm{i}, \mathrm{k}}$ & 533 & $0.55(0.03)$ & $\mathrm{Y}$ \\
\hline R. microocellata & $29-88$ & $10^{c}$ & $70^{1}$ & 14 & $0.82(0.22)$ & $\mathrm{N}$ \\
\hline R. montagui & $19-(87)$ & $10^{\mathrm{c}}$ & $62^{\mathrm{m}}$ & 66 & $0.48(0.11)$ & $\mathrm{N}$ \\
\hline R. undulata & $27-99$ & na & $70^{\mathrm{h}}$ & 65 & $0.57(0.12)$ & $\mathrm{N}$ \\
\hline Scyliorhinus canicula & $10-85$ & $9-11^{\mathrm{c}}$ & $58^{\mathrm{n}}$ & 981 & $0.49(0.02)$ & $\mathrm{Y}$ \\
\hline Scyliorhinus stellaris & $16-120$ & $16^{\mathrm{c}}$ & $77 / 79^{\mathrm{o}, \mathrm{f}}$ & 238 & $0.58(0.05)$ & $\mathrm{Y}$ \\
\hline Squalus acanthias & $36-101$ & $20-30^{\mathrm{d}}$ & $67^{\mathrm{n}}$ & 9 & nd & $\mathrm{N}$ \\
\hline Galeorhinus galeus & $44-153$ & $30-40^{\mathrm{c}}$ & $(69)^{p}$ & 98 & $0.40(0.09)$ & $\mathrm{Y}$ \\
\hline Mustelus asterias & $28-118$ & $28-30^{\mathrm{e}}$ & $80 / 90^{\circ, \mathrm{f}}$ & 393 & $0.48(0.04)$ & $\mathrm{Y}$ \\
\hline M. mustelus & $27-121$ & $39^{\mathrm{e}}$ & $80^{\circ}$ & 136 & $0.43(0.07)$ & $\mathrm{Y}$ \\
\hline
\end{tabular}

\section{Spatial patterns}

Nine species (those caught at 67 to 1056 stations) were plotted as continuous densities, 4 species (occurring at 13 to 43 stations) were shown as continuous presence probabilities, and the remaining 3 species (occurring at 1 to 5 stations) as point maps (Table 2). The spatial distributions of each species for the period from 1988 to 2008 are shown in Fig. 5, while Table 4 shows the results of the geostatistical analyses for the 13 species mapped by interpolation. Interpolation variances indicated that the reliability of the kriged estimates was lower where sampling stations had been sparser (Figs. 1b \& 6). The rajids Raja brachyura, $R$. microocellata and $R$. montagui did not have any spatial dependence detectable at the survey scale $(Q=0)$; their spatial distributions were patchy across the whole survey area, although they were mainly found in shallow coastal waters. The remaining species showed levels of spatial structuring $(Q)$ varying between $27.6 \%$ (R. clavata) and 81.2\% (Galeorhinus galeus), and average patch diameters between 0.17 dd (Squalus acanthias) and $1.29 \mathrm{dd}$ (Scyliorhinus canicula). Average patch diameters were positively correlated with the species' relative density proportions (Spearman's rank correlation $r_{S}=0.83, n=10$ species, $\mathrm{p}=0.003$ ), indicating that the more abundant species had larger patch diameters. The level of spatial structuring appeared to be unrelated to the species' relative density proportion, with Dasyatis pastinaca and G. galeus actually showing the highest levels of spatial dependence $(Q=79.1$ and $81.2 \%$, respectively).

Leucoraja naevus and Squalus acanthias (each shown as presence probabilities) were only found in shallow coastal areas, on a variety of seabed sediments including mud, sand, gravel and pebble. Raja undulata, Galeorhinus galeus, Mustelus asterias and M. mustelus were most abundant in the western half of the survey area, particularly in the deeper waters of the 'narrows', the area between the Cherbourg Peninsula and Isle of Wight, where the seabed is hard (pebble) and tidal currents strong. These species also showed patches of lower density in some shallower coastal waters in the eastern part of the survey area. There were similar spatial distributions for the 2 Mustelus spp., which are morphologically very similar. This was probably due to misidentifications between the 2 species. The 2 scyliorhinids (Scyliorhinus canicula and Scyliorhinus stellaris) also showed similar spatial distributions to each other, although Scyliorhinus canicula had a broader distribution, extending towards the French and UK coasts, and also along the southeastern UK coast. Both of these scyliorhinids were found mainly on hard seabed sediment types (gravel and pebble), in areas of intermediate to strong tidal currents. Interestingly, the spatial distribution of the thornback ray $R$. clavata overlapped that of Scyliorhinus canicula, although $R$. clavata was also found in shallow sandy areas, sheltered from tidal currents, 

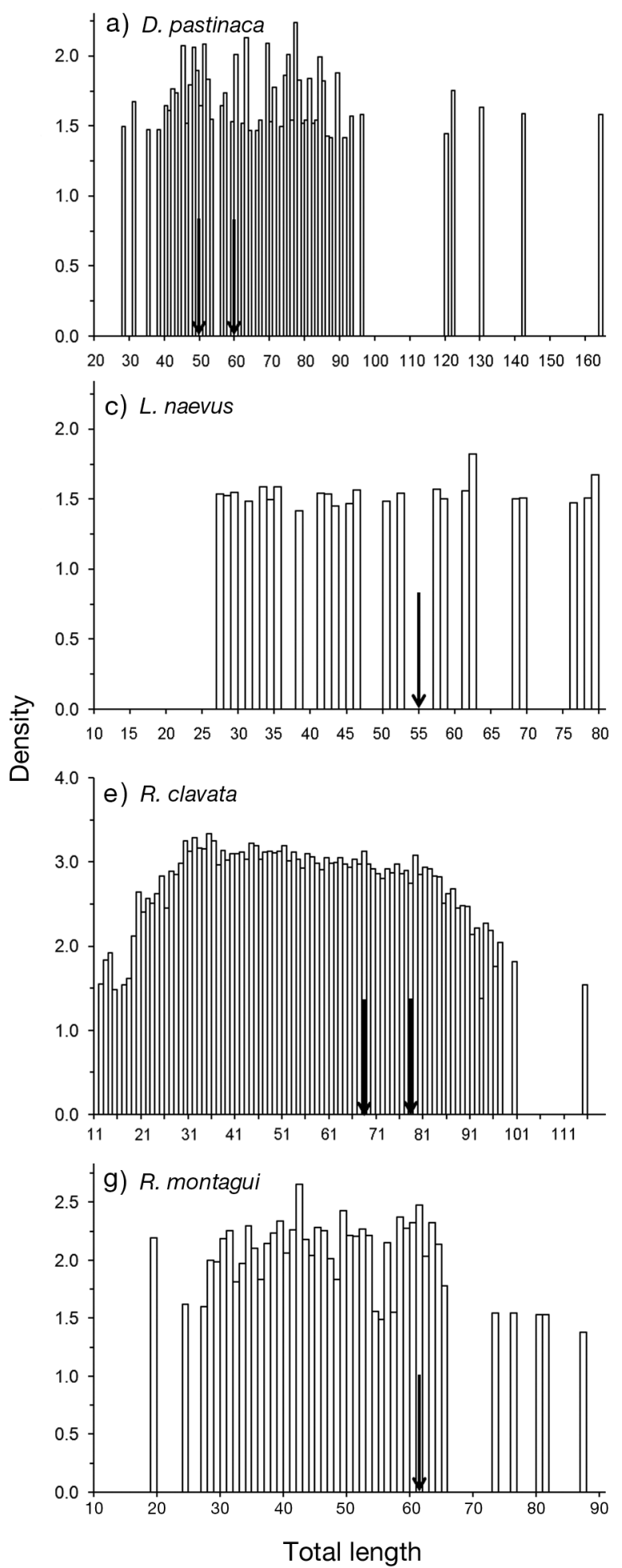
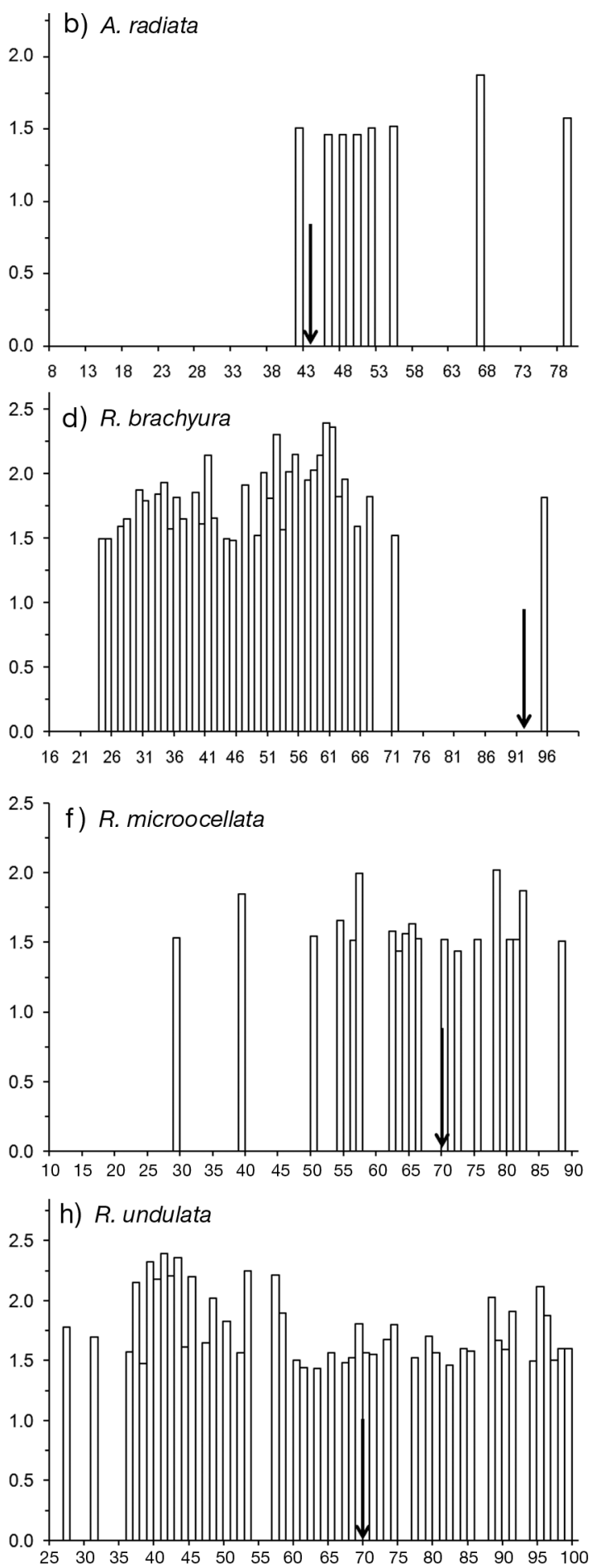

Total length

Fig. 4 (this and facing page). Frequency distributions of total length against density $\left(\log _{10}[x+1], x=\right.$ no. ind. $\left.\mathrm{km}^{-2}\right)$ for $(\mathrm{a})$ Dasyatis pastinaca, (b) Amblyraja radiata, (c) Leucoraja naevus, (d) Raja brachyura, (e) R. clavata, (f) R. microocellata, (g) R. montagui, (h) R. undulata, (i) Scyliorhinus canicula, (j) Scyliorhinus stellaris, (k) Squalus acanthias, (l) Galeorhinus galeus, (m) Mustelus asterias and (n) M. mustelus. Length at $50 \%$ maturity $\left(L_{\mathrm{m}}\right)$ is shown (vertical arrow pointing down), with 2 arrows indicating different values for males and females (see Table 3 for details). Note that $L_{\mathrm{m}}$ value for G. galeus may be too low (J. R. Ellis pers. obs.) and some $A$. radiata and $R$. montagui may have been misidentified (see 'Discussion'). The abscissae approximately start at the published length at birth $\left(L_{\mathrm{b}}\right)$, except for $R$. undulata $\left(L_{\mathrm{b}}\right.$ unknown) and $M$. mustelus $\left(L_{\mathrm{b}}=27 \mathrm{~cm}\right.$ as measured during the Channel Ground Fish Survey, and shorter than that published). Published values for $L_{\mathrm{m}}$ and $L_{\mathrm{b}}$ are listed in Table 3 

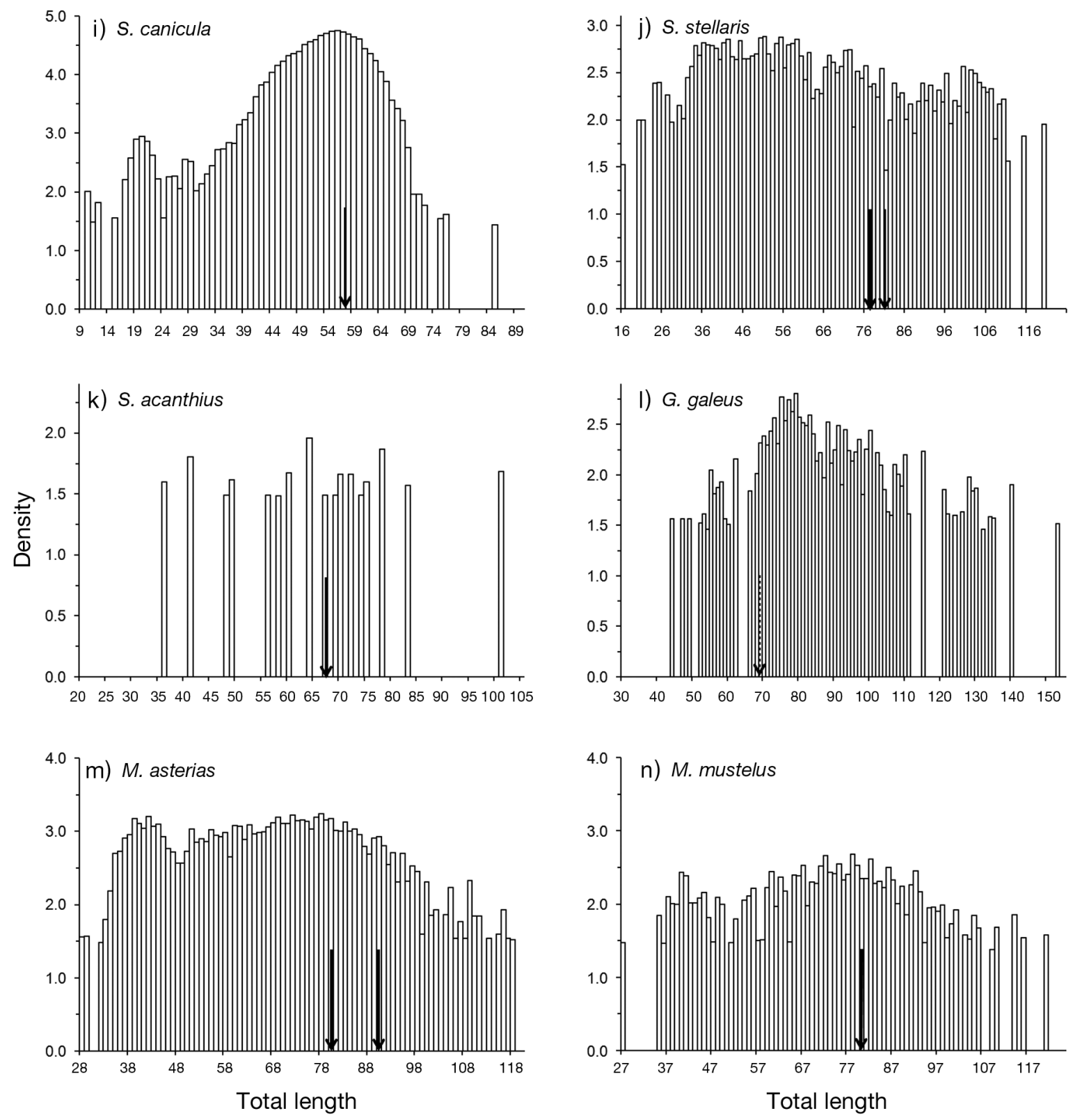

Fig. 4 (continued)

near the French and UK coasts. Finally, Dasyatis pastinaca was found on gravelly seabed bottoms, offshore in deep waters where tidal currents are moderately intense. No species was found exclusively on soft seabed sediment types, although 2 species were found almost exclusively on hard bottoms $(R$. undulata and Scyliorhinus stellaris).

Spatial segregation by sex was investigated for 6 species (Fig. 7, Table 3), and Scyliorhinus canicula displayed the most conspicuous sexual segregation, with the proportion of females (relative to total density) greater in shallow, coastal areas than in deeper offshore areas. In contrast, the proportion of Galeorhinus galeus females tended to be higher offshore, resulting in females being found in the deeper zones of this species distribution, while males displayed a broader spatial distribution. The proportion of $S$. stellaris males was higher within a latitudinal band crossing the surveyed area in its central part: this resulted in males being preferentially found in the central part of the distribution, with females found both there and in the western part of the study area. Spatial segregation by 

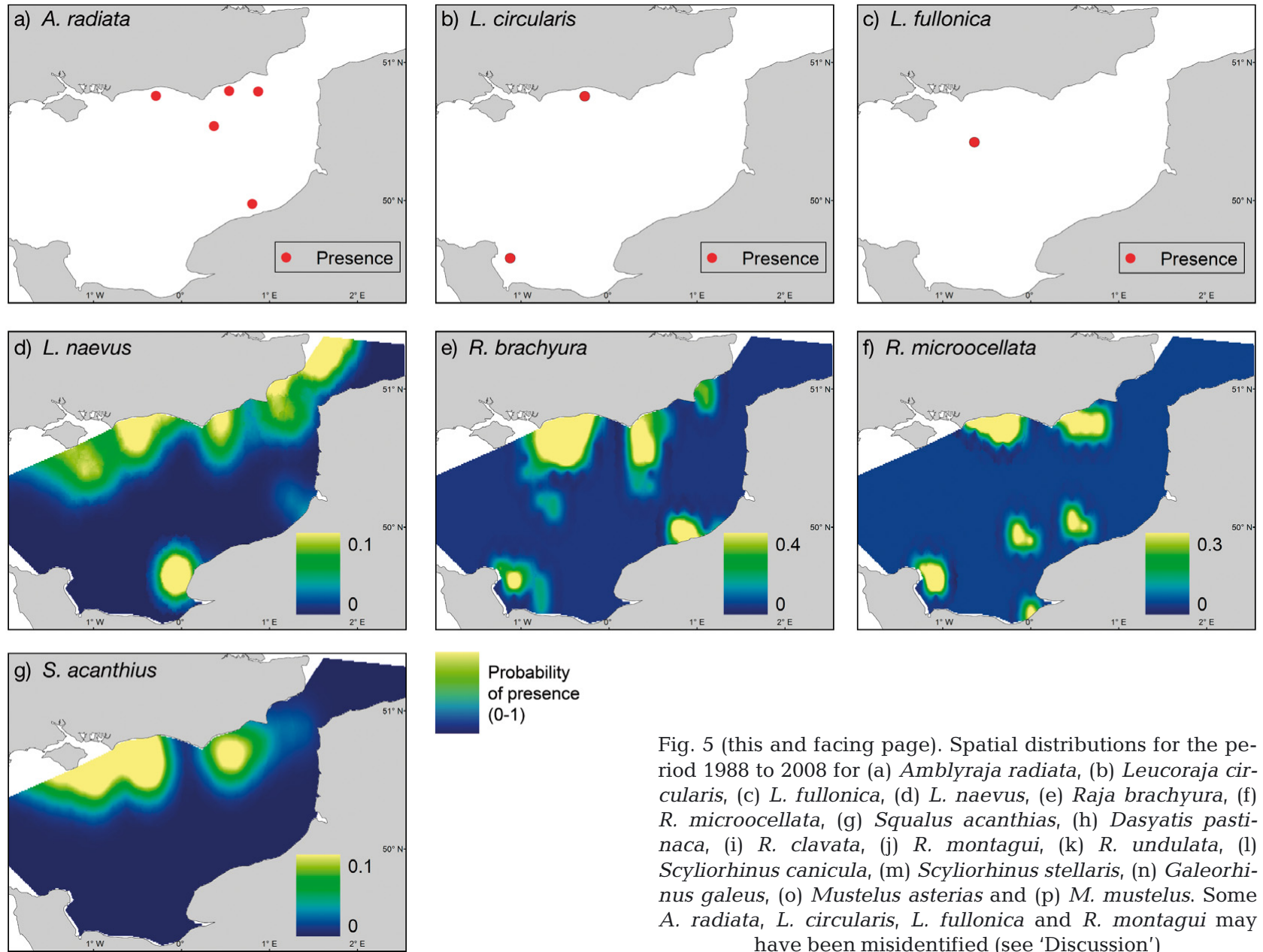

Probability of presence $(0-1)$
Table 4. Geostatistical analyses performed on binary (presence-absence) and density data for 13 elasmobranch species. For each species, the variogram type and fit (i.e. the percentage of variance explained by the chosen geostatistical model) are given, along with the level $(Q)$ of spatial structuring (i.e. the proportion of data variability) explained by the variogram, and the average diameter of patches $(D)$. dd: decimal degrees $(0.1 \mathrm{dd}$ of latitude $\approx 11.4 \mathrm{~km})$, na: not applilcable

\begin{tabular}{|lccccc|}
\hline Species & Data & $\begin{array}{c}\text { Variogram } \\
\text { type }\end{array}$ & $\begin{array}{c}\text { Variogram } \\
\text { fit (\%) }\end{array}$ & $\begin{array}{c}Q \\
(\%)\end{array}$ & $\begin{array}{c}D \\
(\mathrm{dd})\end{array}$ \\
\hline Dasyatis pastinaca & Density & Exponential & 98.9 & 79.0 & 0.48 \\
Leucoraja naevus & Binary & Exponential & 23.2 & 55.1 & 0.21 \\
Raja brachyura & Binary & Bounded linear & na & 0 & na \\
R. clavata & Density & Spherical & 98.9 & 27.6 & 0.85 \\
R. microocellata & Binary & Bounded linear & na & 0 & na \\
R. montagui & Density & Bounded linear & na & 0 & na \\
R. undulata & Density & Circular & 91.1 & 30.7 & 0.98 \\
Scyliorhinus canicula & Density & Spherical & 99.8 & 54.2 & 1.29 \\
Scyliorhinus stellaris & Density & Pentaspherical & 99.4 & 78.3 & 0.88 \\
Squalus acanthias & Binary & Circular & 97.3 & 29.8 & 0.17 \\
Galeorhinus galeus & Density & Circular & 95.9 & 81.1 & 0.52 \\
Mustelus asterias & Density & Pentaspherical & 98.6 & 47.5 & 0.98 \\
M. mustelus & Density & Circular & 94.4 & 37.9 & 0.83 \\
\hline
\end{tabular}

sex, if any, was not as pronounced at the spatial scale of the survey for the remaining 3 species for which this was investigated.

The combined maps (Fig. 8) highlight 2 main zones where elasmobranchs were very rarely captured during the surveys: one relatively large band in the eastern part of the survey area, beyond the UK coastal waters and ranging from the Belgian border to Dieppe, and a smaller area between the Bays of Seine and Veys. Most skates tended to predominantly occupy coastal areas, in contrast to the demersal sharks. The rarely caught skates (Amblyraja radiata, Leucoraja circularis and L. fullonica) were captured in locations consistent with the combined skate map. Despite some overlap 

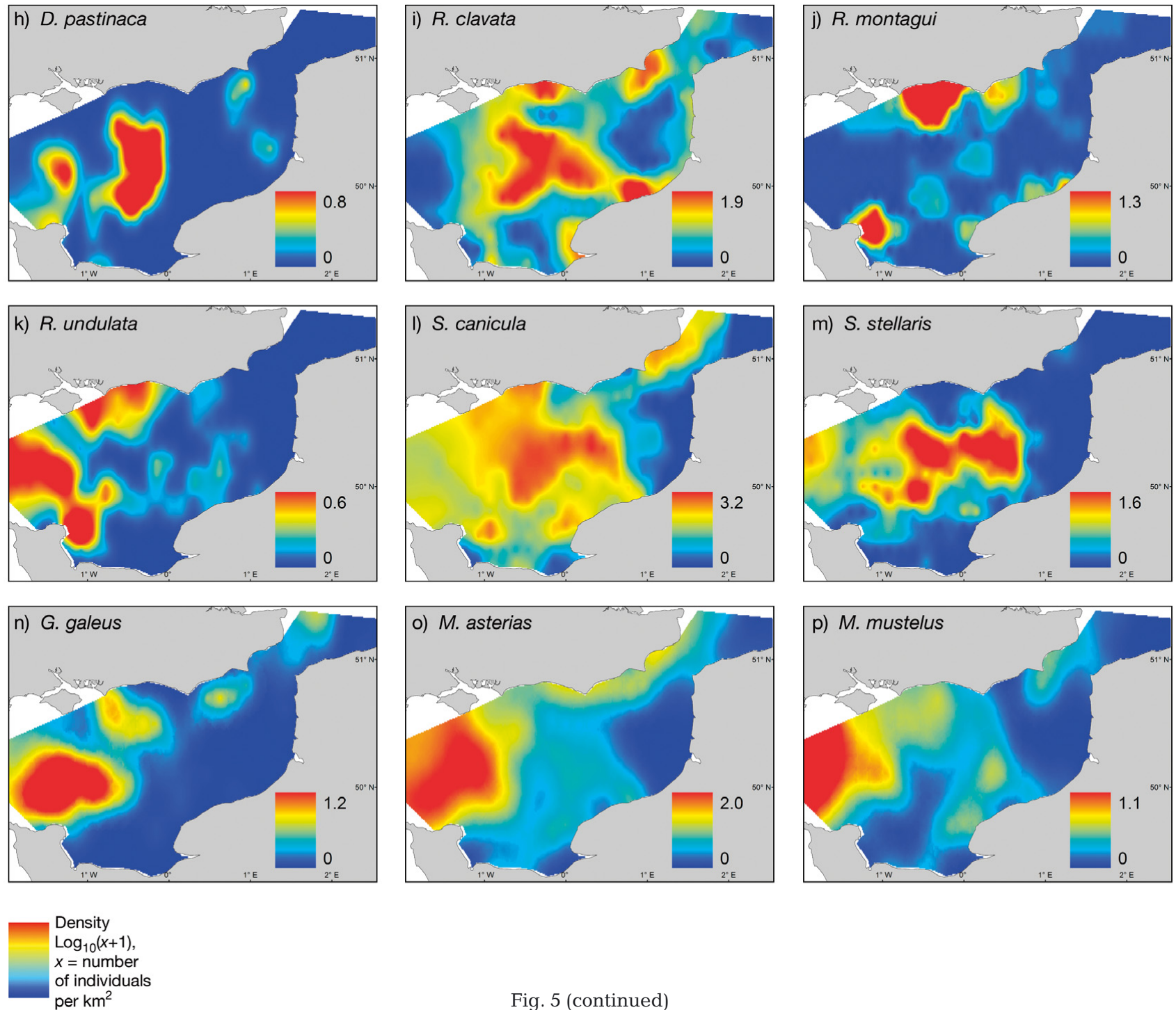

Fig. 5 (continued)

between the shark and skate spatial distributions, the combined maps revealed that most skates (except for Raja undulata) were absent from the deeper waters of the 'narrows', where bottoms are hard and tidal currents strong.

\section{DISCUSSION}

Despite the restrictions imposed by a data set where a number of species were infrequent, the present study has contributed to a greater understanding of the occurrence of elasmobranchs in the eastern English Channel. The temporal (2 decades) and spatial (regional sea) scales of the analysis, along with the number of elasmobranch species considered (16) and the gear used (bottom trawl), were unprecedented. Addi- tionally, it was the first time that such a combination of mapping approaches (involving geostatistics and GIS calculation) was used to gain new insights into the spatial ecology of these species in terms of patch sizes and extent of spatial structure, segregation by sex and also taxonomic group (sharks versus skates). Hence, the results are not just of regional interest, as the methodologies are transferable to other surveys and to other groups of species for which there may be a large number of zero hauls.

\section{Species captured}

Fourteen of the 16 elasmobranch species captured were demersal, and only 2 (Squalus acanthias and Galeorhinus galeus) were benthopelagic (Froese \& 

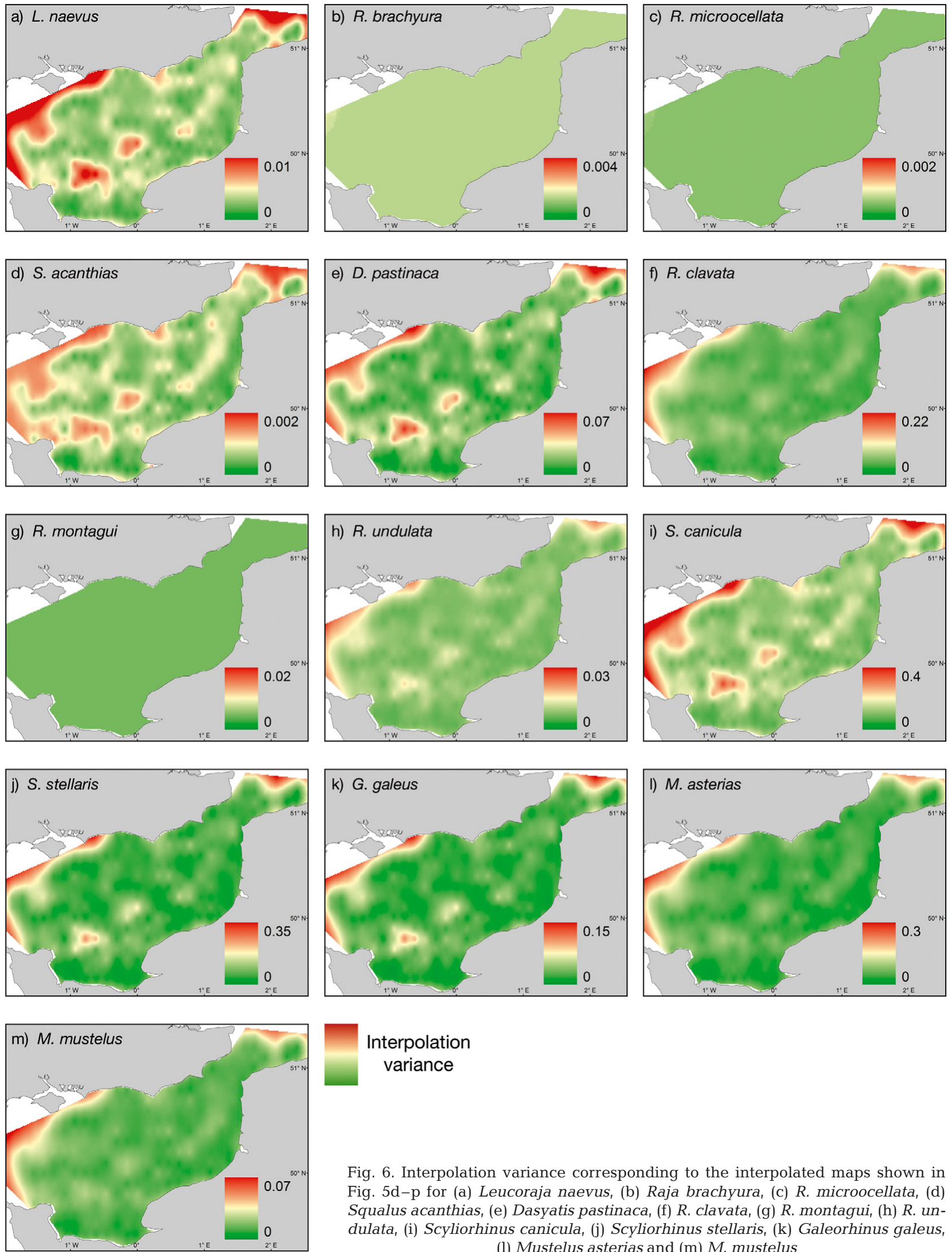

\section{Interpolation variance}

Fig. 6. Interpolation variance corresponding to the interpolated maps shown in Fig. 5d-p for (a) Leucoraja naevus, (b) Raja brachyura, (c) R. microocellata, (d) Squalus acanthias, (e) Dasyatis pastinaca, (f) R. clavata, (g) R. montagui, (h) R. undulata, (i) Scyliorhinus canicula, (j) Scyliorhinus stellaris, (k) Galeorhinus galeus, (l) Mustelus asterias and (m) M. mustelus 

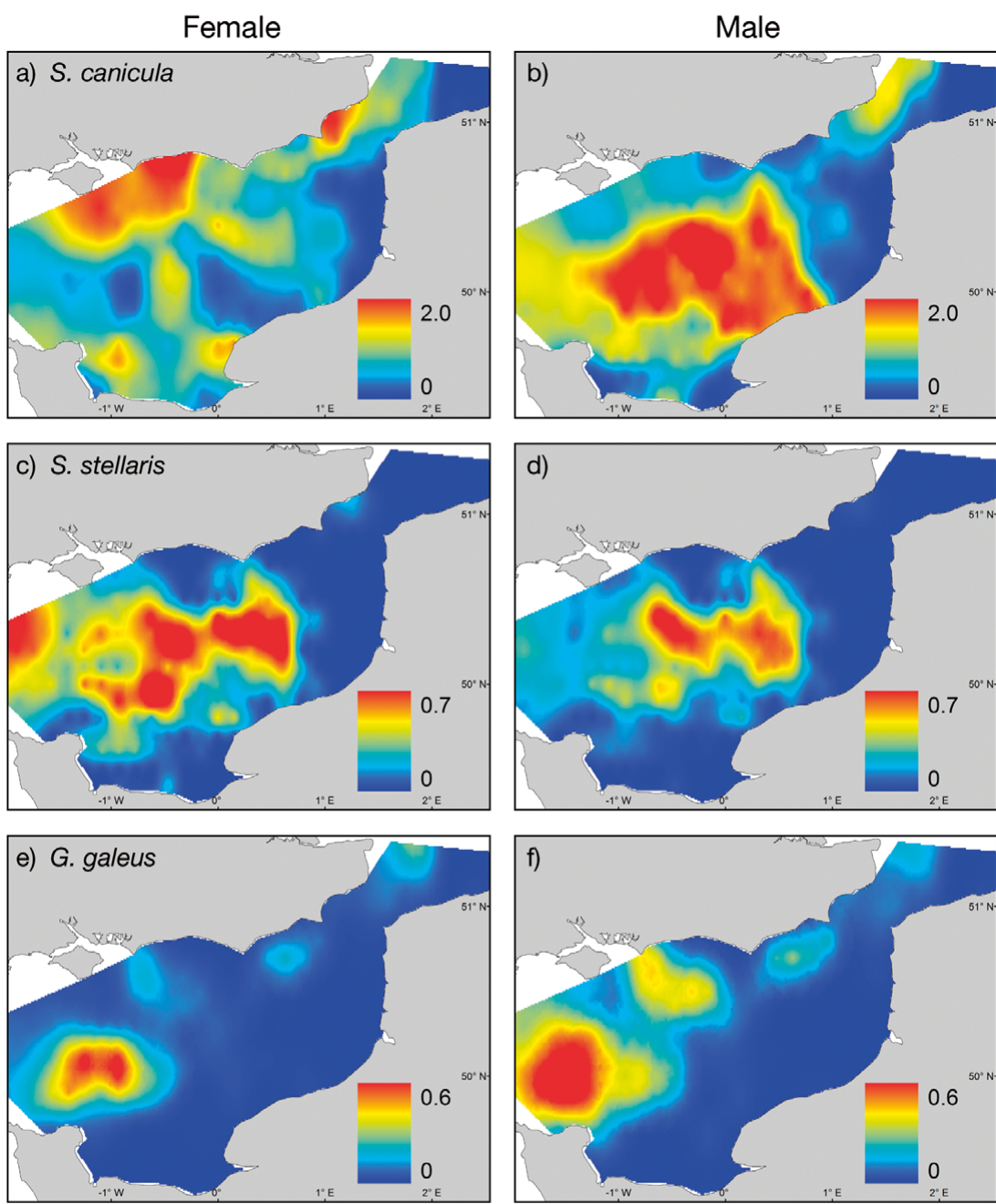

Fig. 7. Spatial distributions of $(a, c, e)$ females and $(b, d, f)$ males of (a,b) Scyliorhinus canicula, (c,d) S. stellaris and (e,f) Galeorhinus galeus, resulting from weighing total densities from

Fig. 5 by interpolated proportions of females and males

\section{Species misidentification}

Misidentifications of elasmobranchs are not infrequent, and skates and Mustelus spp. are known to be problematic taxa in surveys (Daan 2001). As Leucoraja fullonica (1 individual) and L. circularis (2 individuals) (Fig. 5b,c) tend to occur further offshore (Ellis et al. 2005a), these records could represent misidentified Raja microocellata. The larger individuals of Amblyraja radiata and $R$. montagui (Fig. 4b,g, Table 3) may have been $R$. clavata and $R$. brachyura, respectively. Additionally, there is taxonomic confusion between the 2 Mustelus spp. (Serena et al. 2004), and $M$. asterias with faint spots can often be erroneously reported as M. mustelus.

\section{Species catchability}

With the exception of Raja clavata, the batoids were less frequently captured than most of the demersal sharks (except for Squalus acanthias). For some species, densities were low because these species occur only rarely in the study area (Ellis et al. 2005a). This said, the results suggest that GOV trawl selectivity of batoids may be lower than for other demersal elasmobranchs (sharks), as also suggested by Daan et al. (2005) for North Sea elasmobranchs. Gear selectivity of the younger stages of skates and rays may be even lower, since only the

Pauly 2010). During the period from 1988 to 2008, catches were dominated by Scyliorhinus canicula (one of the most abundant elasmobranchs in the Northeast Atlantic; Ellis et al. 2008b), Raja clavata (one of the most abundant skates in north European coastal waters; Ellis 2005) and Mustelus asterias. M. asterias was more abundant than $M$. mustelus, as reported by others for the Northeast Atlantic (Serena et al. 2004, 2006). The absence from the surveys (despite $886 \mathrm{~h}$ of fishing) of 2 demersal species (the white skate Rostroraja alba and the angel shark Squatina squatina), which are known to have occurred in the English Channel (Le Danois 1913) and known to have declined, supports earlier findings in this region (Dulvy et al. 2000, Ellis et al. 2005a). neonates of 1 skate species ( $R$. clavata) were caught, while the neonates of 4 out of 6 shark species were caught by the GOV trawl used during the survey. The beam trawl used during the English summer survey in the same area catches these younger skates more efficiently than larger individuals (Ellis et al. 2005b). Indeed, it has been shown that beam trawls may be more effective at sampling smaller-sized skates, and conversely, GOV trawls may be more effective at sampling larger skates (see ICES 2005). Overall, GOV trawl selectivity for skates can be said to be lower than that of the beam trawl when relative densities are compared, while the converse can be said for sharks (Ellis et al. 2005b, Parker-Humphreys 2005).

Another factor contributing to catchability is species availability, i.e. the proportion of the habitat area of a 

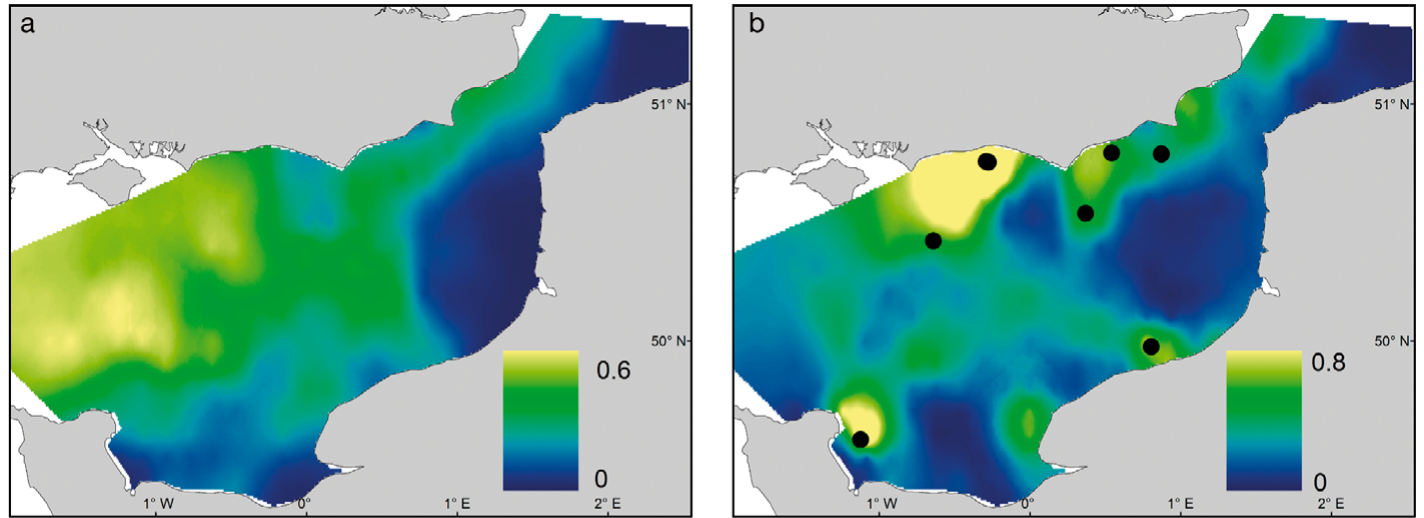

Probability of presence $(0-1)$
Fig. 8. Spatial distributions of (a) sharks and (b) skates for the period 1988 to 2008 Stations where nominal records of Amblyraja radiata, Leucoraja circularis and L. fullonica were made are shown (0) population actually surveyed (Musick \& Bonfil 2005). Hence, seasonal variations in species density could also have contributed to differences in species catchability in the (summer) beam and (autumn) GOV trawl surveys. If part or all of a population seasonally migrates in or out of the area surveyed, this will lead to seasonal variations in catchability for that species. For instance, Squalus acanthias (Holden 1965) and Galeorhinus galeus (Knijn et al. 1993) are known to move to the North Sea in the summer and migrate south in the winter. Hence, a paired study taking place during the same season would be required to test for differences in species catchability due to gear selectivity.

\section{Temporal trends}

Trends in relative abundance (decline, stability or recovery) are 1 of 5 criteria used by the International Union for Conservation of Nature (IUCN) to assess species conservation status and set conservation priorities (IUCN 2008). Most elasmobranchs in the Northeast Atlantic have been assessed using IUCN criteria (our Table 1, Gibson et al. 2008) and, of the 16 species in the present study, the status of Leucoraja circularis (Vulnerable), Raja undulata (Endangered) and Squalus acanthias (Critically Endangered) are of most concern. Two species, $R$. montagui (evaluated as Least Concern) and Galeorhinus galeus (evaluated as Data Deficient, essentially caught as bycatch; Shotton 1999), appeared to be decreasing in relative abundance during the survey period, but these species may not be effectively sampled by the GOV trawl. Indeed, R. montagui is commonly landed in fisheries (though not often targeted) and its small body size suggests that it may be less impacted by fisheries than larger-bodied skate species (Dulvy et al. 2000, Ellis et al. 2007). Although catches have been reported to be stable in the English Channel (Ellis et al. 2005b), with catches over the most recent decade seeming stable, the possible longerterm decline detected in the present study and the fact that a good proportion of individuals caught were immature should be of some concern. Despite some directed longlining and gillnetting for $R$. clavata, this skate is also mainly landed as bycatch (Ellis 2005). The present study does not indicate a clear decline in mean density, at least not since the early 1990s. G. galeus and Mustelus mustelus were evaluated as Data Deficient in the Northeast Atlantic as a result of limited biological information and because landings data are often aggregated as 'dogfish and hounds' (Walker et al. 2006). Hence the temporal density trends presented here are a useful contribution to the determination of the current status of these 2 species in the eastern English Channel.

Out of the 3 species (Scyliorhinus canicula, S. stellaris and Mustelus asterias) for which a potential increase in density was noted, solely $S$. stellaris was of some concern to the IUCN, which evaluated it as Near Threatened due to its large size and patchy distribution. After peaking at about $350 \mathrm{t}$ in 1991-1992, French landings of $S$. stellaris have declined to, and stabilised at, about $60 \mathrm{t}$ annually (Carpentier et al. 2009) since 1994. The data published in the literature remain insufficient to fully assess this species' status and data presented herein suggest that a large proportion of individuals caught were probably immature. The latter holds true for S. canicula, though evaluated as Least Concern and believed to be stable in the English Channel (Ellis et al. 2005b). Finally, survey trends for M. asterias appear to be stable (Ellis et al. 2005b), in coherence with the temporal trend presented here. 
Density data presented here for the benthopelagic Squalus acanthias are likely to reflect a combination of low occurrence in the area surveyed (which may also be a seasonal effect), low gear selectivity, and the fact that the stock is considered depleted (Hammond \& Ellis 2005). Furthermore, trawl catches for this species may not be an adequate indicator of stock status given its tendency to aggregate (Pawson 1995, Fordham et al. 2006). Such behaviour was illustrated by the fact that a quarter of all individuals caught originated from a single station in 1991. In the Northeast Atlantic and worldwide, this species is mainly threatened by bycatch (Fordham et al. 2006) and by targeted fisheries taking advantage of its habit to aggregate by size and sex (Shotton 1999). UK and French landings trends available for the area and for the period from 1989 to 2006 are consistent with this. They show recent landings declining from 120 t in 2000 to <19 t in 2006 (Carpentier et al. 2009), in line with the decline observed for the entire ICES area (total landings recently accounted for $17 \%$ of peak landings; Fordham et al. 2006). This species (considered to be Critically Endangered in the Northeast Atlantic, according to IUCN criteria) has traditionally been the most commercially important elasmobranch in the Northeast Atlantic, and effective management is needed in order to help rebuild the stock.

The data presented here suggest that Raja undulata is stable in the eastern English Channel, which is consistent with it being reported as present in most years of the English beam trawl survey taking place in the same area (Coelho et al. 2003). This species was most abundant off the Isle of Wight and in the 'narrows' and is also known to be locally abundant in parts of the western English Channel (e.g. around the Channel Islands).

\section{Total lengths and sex}

Based on their total lengths and published lengths at $50 \%$ maturity $\left(L_{\mathrm{m}}\right)$, a high proportion of individuals from 7 species were captured as immature, suggesting that either there is a low catchability of mature fish, or that adults occupy other areas, or that the larger, mature, individuals of these stocks could be suffering from over-exploitation. One such species was Raja brachyura, of which almost all individuals were immature. Despite its economic importance, little is known about this species' spatial distribution. It should be emphasised here that published $L_{\mathrm{m}}$ values for the actual study area could not always be found, and that those of other areas were used as a proxy (e.g. the Mediterranean for Dasyatis pastinaca, Scyliorhinus stellaris and the 2 Mustelus spp.). Nonetheless, given the limiting life-history characteristics of elasmo- branchs, management measures could be put in place to reduce fishing impacts on those individuals that have not yet had the chance to reproduce. Such measures could include minimum landing sizes (as is the case for skates and rays through by-laws in some UK inshore waters), spatial management and technical modifications to fishing gear aimed at reducing unwanted bycatch.

The results for 2 species indicated that there was a higher proportion of females. These calculations should, however, be taken with caution because sex data were only available for a small number of stations (40 stations for Dasyatis pastinaca and 14 for Raja microocellata). Also, sex ratios are more likely to be skewed when few individuals are caught at a given station. Spatial variations in the sex ratios of various species are discussed below ('Spatial patterns').

\section{Spatial patterns}

Thirteen species could be mapped continuously and the associated geostatistical analyses provided a quantitative account that was coherent with the spatial patterns observed. The more abundant species tended to display larger patch diameters than less-frequently caught species. As a population grows in size, its distribution range expands into suboptimal habitats (Sutherland 1983, Blanchard et al. 2005) and associated patch diameters increase in size. Future studies using annually interpolated maps so as to study inter-annual variations in spatial occupancy and to detect potential occasional and recurrent areas could usefully be undertaken for the most abundant species in this survey (Raja clavata, Scyliorhinus canicula and Mustelus asterias), including their important life-history stages.

Spatial patterns varied significantly with the species considered, and reflected different habitat utilisation in terms of seabed sediment type, depth and tidal current intensity (maps of which can be found in Carpentier et al. 2009). Leucoraja naevus was found to have a very coastal distribution, notably with a strong presence along the UK coast, although it is usually most common on offshore grounds (Ellis et al. 2005a). Raja brachyura and $R$. montagui were also distributed coastally, as was the case in the English summer survey in the same area (Ellis et al. 2005a, ParkerHumphreys 2005). Scyliorhinus stellaris was mainly found on hard bottoms, as reported elsewhere (Ellis et al. 2006). Although some Mustelus asterias were distributed in sandy areas along the coast, as reported elsewhere (Ellis et al. 2005a), the majority were found offshore in a broad patch in the deeper 'narrows' where there are hard substrata. In contrast to previous studies reporting that its congener, $M$. mustelus, was 
usually found in shallow waters on sandy and muddy bottoms (see Serena et al. 2004), the species had a similar spatial distribution to that of $M$. asterias but was less frequently observed in coastal areas. Out of the 9 skate species, only $R$. clavata and $R$. undulata were found offshore, although $R$. undulata has elsewhere been reported to be more common in shallow waters, especially in terms of the juveniles (Coelho et al. 2003, Parker-Humphreys 2005).

Spatial segregation by sex, where investigated, was evident only for 1 shark species (Scyliorhinus canicula), though detectable for 2 other shark species (its congener S. stellaris and also Galeorhinus galeus). For the other species investigated, sexual segregation may be occurring at spatial scales that are finer than those of the CGFS survey. S. canicula are known to aggregate by sex, and this has also been demonstrated in fine-scale surveys in a sea lough (Sims et al. 2001, Sims 2003). The present study has shown that $S$. canicula is clearly spatially segregated by sex in the eastern English Channel in October, with higher proportions of females in shallower areas and conversely for males, and so broader scale patterns in sexual segregation also occur. Mating is known to take place from May to September with a peak in July (Ellis \& Shackley 1997). In the summer this species (both sexes) is located in the central waters of the eastern English Channel (Carpentier et al. 2009), as opposed to its much broader spatial distribution in the autumn when mating has finished and males and females are found to be geographically segregated (the present study). It is possible that females move towards coastal feeding grounds before males do, as the diet of $S$. canicula is often dominated by invertebrates that are abundant in such habitats (Ellis et al. 1996). Alternatively, the geographical segregation detected at this scale for S. canicula, S. stellaris and G. galeus may reflect male-avoidance behaviour by females, given that courtship and mating in sharks are energetically demanding (Sims et al. 2001, Sims 2003, Mucientes et al. 2009). There is evidence of spatial segregation by sex for Raja clavata (Rousset 1990, Pawson 1995), but no such pattern could be detected for this species at the time of the survey (October), at least on the spatial scale investigated. This may also be due to sexual segregation being less pronounced in juveniles.

Further investigation involving habitat modelling should help unravel and quantify habitat utilisation more precisely by statistically testing a set of environmental factors including depth, seabed sediment type, salinity and temperature (Vaz et al. 2008). The results would enable researchers to quantify the potential impact of habitat degradation or loss (e.g. through dredging, aggregate extraction, pollution) on these species. Depending on the species, it might be neces- sary to separate data by sex and/or life stages (the latter based on length frequency distributions). Considering these variables, the locations and surface areas occupied might differ significantly, which would have implications for the spatial management of vulnerable individuals, e.g. juveniles (here shown to account for significant proportions of the individuals of 7 species), but also for reproductively active females. Scyliorhinus canicula (Sims et al. 2001, Ellis et al. 2008b), Squalus acanthias (Pawson 1995, Fordham et al. 2006) and Galeorhinus galeus (Walker et al. 2006), for instance, are all known to aggregate by size and sex as a consequence of differences in behaviour and/or habitat use. In the present study, the first peak in the bimodal length distributions of Scyliorhinus canicula, and also Mustelus asterias and M. mustelus, probably resulted from capturing individuals in their first and/or second years of life. Younger individuals may be more limited in their swimming and competitive abilities than older ones and hence may be confined to particular areas, such as shallower coastal nurseries sheltered from strong tidal currents. In effect, this was found to be the case for Scyliorhinus canicula in the eastern English Channel during the UK summer survey in the same area, with smaller individuals found in shallow inshore areas and larger individuals in deeper offshore waters (Carpentier et al. 2009). Likewise, geographical sexual segregation could lead to a differential availability of sexes to the fishery and hence a sex-biased exploitation so that important components of the population, such as reproductively active females, could be impacted (Mucientes et al. 2009). There is also a biological rationale for trying to reduce fishing mortality for the larger mature females, as it is often reported that larger females produce more (and larger) eggs/young (see Ellis et al. 2008a).

Daan et al. (2005) showed that there was a clear eastwest gradient in elasmobranch biodiversity in the North Sea. The shark and skate maps produced in the present study were helpful in revealing areas of relative elasmobranch absence, and areas where more species of the skate or the shark groups tended to be found. The fact that sharks tended to be located in the deeper waters of the eastern English Channel could explain why they were comparatively less caught by the more coastal English summer survey (ParkerHumphreys 2005), although it is recognised that beam trawl surveys have a lower catch efficiency for the faster-moving triakid and squaliform sharks. Management measures could make use of this knowledge on the spatial distribution of the shark and skate groups to reduce fishing impact in those areas where comparatively large numbers of elasmobranch species, or important life-history stages of particular species, are found. 


\section{CONCLUSIONS}

Intermediate temporal trends in density, length and sex frequencies and a quantitative investigation into each species' spatial ecology provided essential information to the much-needed overall monitoring of a group that is vulnerable to over-fishing, habitat degradation and other anthropogenic disturbance. This knowledge can be used in future marine spatial planning of the multi-use cross-border eastern English Channel, where there are important fisheries, international shipping and freight, ferries, tourism and leisure (Carpentier et al. 2009, Martin et al. 2009) and also for the assessment and development of regional management for the demersal elasmobranchs in the area and elsewhere.

Acknowledgements. Part of the work was co-financed by the European Union through its European Regional Development Fund (INTERREG 3a CHARM II project 162/039/365). We thank the GENAVIR crew and the scientific staff of the RV 'Gwen-Drez'. We are grateful to the reviewers for their comments, which have helped improve the manuscript, and to K. Urbantat for correcting the English. C.S.M. carried out some of the work with funding from the European Union (Marie-Curie IEF FP7-PEOPLE-IEF-2008, grant 235791).

\section{LITERATURE CITED}

Blanchard JL, Mills C, Jennings S, Fox CJ, Rackham BD, Eastwood PD, O'Brien CM (2005) Distribution-abundance relationships for North Sea Atlantic cod (Gadus morhua): observation versus theory. Can J Fish Aquat Sci 62: 2001-2009

Bonfil R (1994) Overview of world elasmobranch fisheries. FAO Fish Tech Pap 341

Carpentier A, Martin CS, Vaz S (eds) (2009) Channel habitat atlas for marine resource management (CHARM phase II), INTERREG 3a Programme. IFREMER, Boulogne-sur-mer

Castro JI (1983) The sharks of North American waters. Texas A \& M University Press, College Station, TX

Coelho R, Bertozzi M, Ungaro N, Ellis JR (2003) Raja undulata. In: IUCN Red List of threatened species, version 2009.2. Accessed 8 Mar 2010. www.iucnredlist.org

Compagno LJV, Dando M, Fowler SL (2005) Sharks of the world. Harper Collins, London

Coppin F, Le Roy D, Schlaich Y (2001) Channel Ground Fish Survey (CGFS) handbook. Report no. 09/2001-DRV/ RH/DT. IFREMER, Brest

Daan N (2001) The IBTS database: a plea for quality control. Proc ICES Annu Sci Conf, 26-29 Sep 2001, Oslo. CM 2001/T:03

Daan N, Heessen H, ter Hofstede R (2005) North Sea elasmobranchs: distribution, abundance and biodiversity. Proc ICES Annu Sci Conf, 20-24 Sep 2005, Aberdeen. CM 2005/N:06

Dorel D (1986) Poissons de l'Atlantique nord-est relations taille-poids. Report DRV-86-001/RH/NANTES. IFREMER, Nantes

Dulvy NK, Reynolds JD (2002) Predicting extinction vulnerability in skates. Conserv Biol 16:440-450

Dulvy NK, Metcalfe JD, Glanville J, Pawson MG, Reynolds JD (2000) Fishery stability, local extinctions, and shifts in community structure in skates. Conserv Biol 14:283-293
Ellis JR (2005) Raja clavata. IUCN Red List of threatened species, version 2009.2. Accessed 8 Mar 2010. www. iucnredlist.org

Ellis JR, Shackley SE (1997) The reproductive biology of Scyliorhinus canicula in the Bristol Channel, UK. J Fish Biol 51:361-372

Ellis JR, Pawson MG, Shackley SE (1996) The comparative feeding ecology of six species of shark and four species of ray (Elasmobranchii) in the North-East Atlantic. J Mar Biol Assoc UK 76:89-106

Ellis JR, Cruz-Martinez A, Rackham BD, Rogers SI (2005a) The distribution of chondrichthyan fishes around the British Isles and implications for conservation. J Northwest Atl Fish Sci 35:195-213

Ellis JR, Dulvy NK, Jennings S, Parker-Humphreys M, Rogers SI (2005b) Assessing the status of demersal elasmobranchs in UK waters: a review. J Mar Biol Assoc UK 85: 1025-1047

Ellis JR, Serena F, Mancusi C, Haka F, Morey G, Guallart J, Schembri T (2006) Scyliorhinus stellaris. IUCN Red List of threatened species, version 2009.2. Accessed 8 Mar 2010. www.iucnredlist.org

Ellis JR, Ungaro N, Serena F, Dulvy N and others (2007) Raja montagui. IUCN Red List of threatened species, version 2009.2. Accessed 8 Mar 2010. www.iucnredlist. org

Ellis JR, Clarke MW, Cortés E, Heessen HJL, Apostolaki P, Carlson JK, Kulka DW (2008a) Management of elasmobranch fisheries in the North Atlantic. In: Payne AIL, Cotter AJ, Potter ECE (eds) Advances in fisheries science. 50 years on from Beverton and Holt. Blackwell Publishing, Oxford

Ellis JR, Mancusi C, Serena F, Haka F and others (2008b) Scyliorhinus canicula. IUCN Red List of threatened species, version 2009.2. Accessed 8 Mar 2010. www. iucnredlist.org

Fischer M, Schneider M, Bauchot ML (eds) (1987) Fiches FAO d'identification des espèces pour les besoins de la pêche. Méditerranée et mer Noire, zone de pêche 37, révision 1, Vol II. FAO, Rome

Fordham S, Fowler SL, Coelho R, Goldman KJ, Francis M (2006) Squalus acanthias. IUCN Red List of threatened species, version 2009.2. Version (01/2010) Accessed 8 Mar 2010. www.iucnredlist.org

Froese F, Pauly D (eds) (2010) FishBase World Wide Web electronic publication. Accessed 8 Mar 2010. www.fishbase.org

Gibson C, Valenti SV, Fordham SV, Fowler SL (2008) The conservation of Northeast Atlantic chondrichthyans: report of the IUCN Shark Specialist Group. Northeast Atlantic Red List Workshop, Nature Bureau, Newbury

Hammond TR, Ellis JR (2005) Bayesian assessment of Northeast Atlantic spurdog using a stock production model, with prior for intrinsic population growth rate set by demographic methods. J Northwest Atl Fish Sci 35:299-308

Holden MJ (1965) The stocks of spurdog (Squalus acanthias L.) in British waters and their migration. Fish Invest Minist Agric Fish Food (GB) Ser II, No. 24

> Holden MJ, Rout DW, Humphreys CN (1971) The rate of egg laying by three species of ray. J Cons Int Explor Mer 33:335-339

ICES (International Council for the Exploration of the Sea) (1997) Report of the study group on elasmobranchs. ICES Counc Meet Pap 1997/G:2

ICES (2005) Report of the Working Group on Fish Ecology (WGFE). ICES Counc Meet Pap 2005/G:05

ICES (2010) Report of the International Bottom Trawl Survey Working Group (IBTSWG), with Addendum 1: Manual for the IBTS, rev VIII, and Addendum 2: Manual for the IBTS 
in the western and southern areas, rev III. ICES Counc Meet Pap 2010/SSGESST:06

Ismen A (2003) Age, growth, reproduction and food of common stingray (Dasyatis pastinaca L, 1758) in Iskenderun Bay, the eastern Mediterranean. Fish Res 60:169-176

IUCN (International Union for the Conservatioon of Nature) (2008) Guidelines for using the IUCN Red List categories and criteria, version 7.0. Accessed 8 Mar 2010. http://intranet. iucn.org/webfiles/doc/SSC/RedList/RedListGuidelines.pdf

IUCN (2010) IUCN Red List of threatened species, version 2010.1. Accessed 8 Mar 2010. www.iucnredlist.org

> Jennings S, Greenstreet SPR, Reynolds JD (1999) Structural change in an exploited fish community: a consequence of differential fishing effects on species with contrasting life histories. J Anim Ecol 68:617-627

Knijn RJ, Boon TW, Heessen HJL, Hislop JRG (1993) Atlas of North Sea fishes. ICES Coop Res Rep 194

Kulka DW, Sulikowski J, Gedamke J, Pasolini P, Endicott M (2004) Amblyraja radiata. IUCN Red List of threatened species, version 2009.2. Accessed 8 Mar 2010. www.iucnredlist.org

Le Danois E (1913) Contribution à l'étude systématique et biologique des poissons de la Manche occidentale. $\mathrm{PhD}$ thesis, Université de Paris

Legendre P, Legendre L (1998) Numerical ecology. Elsevier, Amsterdam

Mackinson S, Daskalov G (2007) An ecosystem model of the North Sea to support an ecosystem approach to fisheries management: description and parameterisation. Sci Ser Tech Rep 142. Cefas, Lowestoft

Martin CS, Carpentier A, Vaz S, Coppin F and others (2009) The Channel Habitat Atlas for marine Resource Management (CHARM): an aid for planning and decision-making in an area under strong anthropogenic pressure. Aquat Living Resour 22:499-508

Martin CS, Vaz S, Koubbi P, Meaden GJ and others (2010) A digital atlas to link ontogenic shifts in fish spatial distribution to the environment of the eastern English Channel. Dab Limanda limanda as a case study. Cybium 34:59-71

Maxwell D, Jennings S (2005) Power of monitoring programmes to detect decline and recovery of rare and vulnerable fish. J Appl Ecol 42:25-37

Mello LGS, Rose GA (2005) Using geostatistics to quantify seasonal distribution and aggregation patterns of fishes: an example of Atlantic Cod (Gadus morhua). Can J Fish Aquat Sci 62:659-670

Mucientes GR, Queiroz N, Sousa LL, Tarroso P, Sims D (2009) Sexual segregation of pelagic sharks and the potential threat from fisheries. Biol Lett 5:156-159

Musick JA, Bonfil R (eds) (2005) Management techniques for elasmobranch fisheries. FAO Fish Tech Pap 474

Parker-Humphreys M (2005) Distribution and relative abundance of demersal fishes from beam trawl surveys in eastern English Channel (ICES division VIId) and the southern North Sea (ICES division IVc) 1993-2001. Sci Ser Tech Rep 124. Cefas, Lowestoft

Pawson MG (1995) Biogeographical identification of English Channel fish and shellfish stocks. Fish Res Tech Rep 99. Cefas, Lowestoft

Payne RW, Murray DA, Harding SA, Baird DB, Soutar DM (2008) GenStat for Windows (11th edn), Introduction. VSN International, Hemel Hempstead

Editorial responsibility: Stylianos Somarakis, Heraklion, Greece
Petitgas P (2001) Geostatistics in fisheries survey design and stock assessment: models, variances and applications. Fish Fish 2:231-249

Quignard JP, Capapé C (1972) Note sur les espèces Méditerranéennes du genre Mustelus (Selachii, Galeoidea, Triakidae). Rev Trav Inst Peches Marit 36:15-29

Rousset J (1990) Population structure of thornback rays Raja clavata and their movement in the Bay of Douarnenez. J Mar Biol Assoc UK 70:261-268

Serena F, Mancusi C, Clò S, Ellis J, Valenti SV (2004) Mustelus mustelus. IUCN Red List of threatened species, version 2009.2. Accessed 8 Mar 2010. www.iucnredlist.org

Serena F, Mancusi C, Ellis J (2006) Mustelus asterias. IUCN Red List of threatened species, version 2009.2. Accessed 8 Mar 2010. www.iucnredlist.org

Shotton R (ed) (1999) Case studies of the management of elasmobranch fisheries. FAO Fish Tech Pap 378

Sims DW (2003) Tractable models for testing theories about natural strategies: foraging behaviour and habitat selection of free-ranging sharks. J Fish Biol 63(Suppl A): $53-73$

Sims DW, Nash JP, Morritt D (2001) Movements and activity of male and female dogfish in a tidal sea lough: alternative behavioural strategies and apparent sexual segregation. Mar Biol 139:1165-1175

Skjæraasen JE, Bergstad OA (2000) Distribution and feeding ecology of Raja radiata in the northeastern North Sea and Skagerrak (Norwegian Deep). ICES J Mar Sci 57: $1249-1260$

Springer S (1967) Social organization of shark populations. In: Gilbert PW, Mathewson RF, Rall DP (eds) Sharks, skates and rays. Johns Hopkins Press, Baltimore, MD

Stevens JD, Bonfil R, Dulvy NK, Walker P (2000) The effects of fishing on sharks, rays and chimaeras (chondrichthyans), and the implications for marine ecosystems. ICES J Mar Sci 57:476-494

Sutherland WJ (1983) Aggregation and the ideal free distribution. J Anim Ecol 52:821-828

Vaz S, Martin CS, Ernande B, Coppin F, Harrop S, Carpentier A (2005) Using geostatistics to quantify annual distribution and aggregation patterns of fishes in the eastern English Channel. Proc ICES Annu Sci Conf, 20-24 Sep 2005, Aberdeen. Doc. no. CM 2005/L:21

Vaz S, Carpentier A, Coppin F (2007) Eastern English Channel fish assemblages: measuring the structuring effect of habitats on distinct subcommunities. ICES J Mar Sci 64: 271-287

> Vaz S, Martin CS, Eastwood P, Ernande B, Carpentier A, Meaden GJ, Coppin F (2008) Modelling species distributions using regression quantiles. J Appl Ecol 45: $204-217$

Walker PA (1999) Fleeting images: dynamics of North Sea ray populations. PhD dissertation, University of Amsterdam

Walker PA, Heessen HJL (1996) Long-term changes in ray populations in the North Sea. ICES J Mar Sci 53: 1085-1093

Walker TI, Cavanagh RD, Stevens JD, Carlisle AB and others (2006) Galeorhinus galeus. IUCN Red List of threatened species, version 2009.2. Accessed 8 Mar 2010. www. iucnredlist.org

Webster R, Oliver MA (2001) Geostatistics for environmental scientists. Wiley, Chichester

Submitted: May 1, 2010; Accepted: September 2, 2010

Proofs received from author(s): October 29, 2010 